\title{
Efficacy, effectiveness and real life goal attainment of statins in managing cardiovascular risk
}

\author{
Naila Goldenberg',2 \\ Charles Glueck' \\ 'Cholesterol and Metabolism Center \\ of Jewish Hospital, Cincinnati, Ohio, \\ USA; ${ }^{2}$ University of Cincinnati, \\ Division of Endocrinology and \\ Metabolism, Cincinnati, Ohio, USA
}

Correspondence: Charles Glueck 3200 Burnett Ave, Cincinnati, $\mathrm{OH}$ 45229 USA

$\mathrm{Tel}+I 5135857800$

Fax +I 5135857950

Email glueckcj@healthall.com

\begin{abstract}
Statins became available for the treatment of hypercholesterolemia in 1987. Multiple, well-designed, placebo-controlled, double-blind studies revealed that each $1 \%$ reduction in serum cholesterol level was associated with about $1 \%$ reduction in risk of cardiovascular events. Low-density lipoprotein (LDL) cholesterol reduction to less than $78 \mathrm{mg} / \mathrm{dL}$ may be associated with reduction of atheroma burden. Patients with high levels of high specificity C-reactive protein and having LDL cholesterol less than $3.4 \mathrm{mmol} / \mathrm{L}(130 \mathrm{mg} / \mathrm{dL})$ in primary prevention settings benefited from aggressive LDL cholesterol reduction with rosuvastatin over a 2 -year period. However, in real life practice, about half of patients who are prescribed statins discontinue the medication by the end of the year. Medication adherence is lower in younger patients, women, and absence of known coronary heart disease. Personal features of the prescribing physician and dispensing pharmacies also affect patients' compliance. More studies are needed to evaluate if "compliance packets" would benefit patients in a real life situation.
\end{abstract}

Keywords: cardiovascular risk, statin, goal attainment, primary prevention, secondary prevention

\section{Introduction}

Coronary artery disease (CAD) is the most common cause of death in the developed countries in both men and women. Billions of dollars are spent on research and development of new therapies as well for the therapy itself to prevent both the risk of recurrent cardiovascular (CVD) events (secondary prevention) as well as preventing the first ${ }^{\mathrm{t}}$ event (primary prevention). ${ }^{1,2}$ Ever since the connection between cholesterol levels and risk for CAD was established, the goal of lowering total cholesterol and low-density lipoprotein (LDL) cholesterol became a very important health issue. ${ }^{3}$

Based on new evidence, ${ }^{4-6}$ targeted goals for cholesterol lowering have been progressively moved downward to lower levels, and the current modified recommendations by United States National Cholesterol Education Program (NCEP) Adult Treatment Panel III $^{7}$ include the following:

1. LDL cholesterol less than $2.6 \mathrm{mmol} / \mathrm{L}(100 \mathrm{mg} / \mathrm{dL})$ for patients with high risk (10-year risk more than 20\%) for the development of cardiovascular event.

2. LDL cholesterol less than $1.8 \mathrm{mmol} / \mathrm{L}(70 \mathrm{mg} / \mathrm{dL})$ in very high risk populations with previous history of coronary heart disease (CHD) or equivalents (such as diabetes mellitus, carotid artery disease, peripheral artery disease).

3. The recommended goal is less than $3.4 \mathrm{mmol} / \mathrm{L}(130 \mathrm{mg} / \mathrm{dL})$ for patients with moderately high risk ( $2+$ risk factors or 10 year risk $10 \%-20 \%$ ) and less than $2.6 \mathrm{mmol} / \mathrm{L}(100 \mathrm{mg} / \mathrm{dL})$ is optional.

4. In patients with 1 or less risk factors and less than $10 \%$ risk of development of CVD event over the next 10 year the recommended goal is LDL cholesterol less than $4.14 \mathrm{mmol} / \mathrm{L}(160 \mathrm{mg} / \mathrm{dL}){ }^{7}$ 
The Fourth Joint Task Force of the European Society of Cardiology and other societies on cardiovascular disease prevention in clinical practice established the following goals for LDL cholesterol:

1. Less than $3 \mathrm{mmol} / \mathrm{L}(115 \mathrm{mg} / \mathrm{dL})$ for general population.

2. Less than $2.5 \mathrm{mmol} / \mathrm{L}(100 \mathrm{mg} / \mathrm{dL})$ in high risk patients and less than $2.0 \mathrm{mmol} / \mathrm{L}(80 \mathrm{mg} / \mathrm{dL})$ if feasible. ${ }^{8,9}$

\section{Statins and LDL cholesterol level reduction}

Lovastatin, the first inhibitor of the rate-limiting enzyme in the cholesterol biosynthetic pathway, 3-hydroxy-3-methylglutaryl-CoA (HMG-CoA) reductase, was approved by the FDA in 1987 for the treatment of hyperlipidemia. ${ }^{10}$ Since then 7 other statins became available, though cerivastatin was withdrawn from the market in 2001 because of the high rate of serious myopathic side-effects. The mechanism of action of statins includes the reduction of intracellular mevalonate synthesis, the cholesterol precursor. This leads to decrease of regulatory sterol pool. That causes upregulation of LDL receptors and thus increases the uptake of LDL and very low-density lipoprotein (VLDL) particles from blood. Statins are also known to reduce the production of Apo B containing particles by the liver, though this is clearly the secondary mechanism. ${ }^{10}$

Seven statins are currently available: lovastatin, fluvastatin, pravastatin, simvastatin, atorvastatin, pitavastatin and rosuvastatin. Pitavastatin was approved in Japan in July 2003 and later in South Korea and India. It is expected to be available in several European countries from the second half $2010 .{ }^{11}$ Rosuvastatin is the latest addition to the HMG-CoA reductase inhibitor family and became available in the US in 2003. ${ }^{12}$ It has unique properties and, unlike other statins (excepting pravastatin), is hydrophilic. Rosuvastatin, pitavastatin and fluvastatin are metabolized through cytochrome P450 2C9, and have less drug-drug interaction than other statins that are metabolized through the cytochrome P450 3A4 system along with many other commonly used drugs. ${ }^{13}$ Overall, pravastatin, pitavastatin and rosuvastatin undergo little metabolism. ${ }^{14}$

Rosuvastatin is the most potent statin currently approved in the US and Europe, and is associated with about 50\% LDL cholesterol reduction at a $10 \mathrm{mg}$ daily dose. Efficacy and safety of rosuvastatin versus atorvastatin, simvastatin, and pravastatin across doses was studied in the STELLAR study. ${ }^{8}$ STELLAR was a head-to-head study of 2268 adults with LDL cholesterol between 160 and $250 \mathrm{mg} / \mathrm{dL}$. The STELLAR trial evaluated the effect of different doses of rosuvastatin (10-20 and $40 \mathrm{mg} /$ day), atorvastatin, simvastatin (10, 20, 40 or $80 \mathrm{mg} /$ day), and pravastatin $(10,20$ or $40 \mathrm{mg} /$ day). ${ }^{8}$ Patients on rosuvastatin $40 \mathrm{mg} /$ day achieved up to $55 \%$ of LDL cholesterol reduction, on maximal dose of atorvastatin ( $80 \mathrm{mg} /$ day) $51.1 \%$, on simvastatin (80 mg/day) $45.8 \%$, and on pravastatin (40 mg/day) $29.7 \%$. Moreover, patients on rosuvastatin had significant increments in high-density lipoprotein (HDL) cholesterol compared to other statins (Table 1). ${ }^{8}$ A meta-analysis of 164 short studies confirmed the STELLAR findings. ${ }^{15}$ The efficacy of different statins in a dose-dependent manner on lowering LDL cholesterol has been evaluated. The meta-analysis showed that $40 \mathrm{mg}$ of fluvastatin reduced LDL cholesterol on average by $27 \%$, pravastatin by $29 \%$, lovastatin and simvastatin by $37 \%$, atorvastatin by $49 \%$, and rosuvastatin by $53 \%$. Thus rosuvastatin was the most efficacious of all the statins, followed by atorvastatin and simvastatin Table 1). ${ }^{15}$ The STELLAR study ${ }^{8}$ also revealed that the Adult Treatment Panel III LDL cholesterol goal was achieved by $82 \%$ to $89 \%$ of patients treated with rosuvastatin 10 to $40 \mathrm{mg}$ compared with $69 \%$ to $85 \%$ of patients treated with atorvastatin 10 to $80 \mathrm{mg}$. The European LDL cholesterol goal of $<3.0 \mathrm{mmol} / \mathrm{L}$

Table I Low-density lipoprotein (LDL) reduction/ATP III goal achievement in comparison study (STELLAR trial), meta-analysis and in a real life (REALITY) study.

\begin{tabular}{|c|c|c|c|c|c|c|}
\hline & Pravastatin & Lovastatin & Fluvastatin & Simvastatin & Atorvastatin & Rosuvastatin \\
\hline LDL reduction on $40 \mathrm{mg} /$ day (meta-analysis) $)^{15}$ & $29 \%$ & $37 \%$ & $27 \%$ & $37 \%$ & $49 \%$ & $53 \%$ \\
\hline LDL reduction (\%) STELLAR 80 mg/day & $29.7 \%^{*}$ & NA & NA & $38.8 \% *$ & $47.8 \% *$ & $55 \%$ \\
\hline $80 \mathrm{mg} /$ day & NA & NA & NA & $45.8 \% *$ & $51.1 \% *$ & NA \\
\hline $\begin{array}{l}\text { Attainment of ATP III goals (STELLAR) } \\
\text { (\% of patients) })^{8} \text { on maximal dose }\end{array}$ & $54 \%^{*}$ & NA & NA & $82 \%$ & $85 \%$ & $89 \%$ \\
\hline Real life ATP III goal attainment REALITY & $10 \mathrm{mg} 35.9 \%$ & $20.0 \%$ & NA & $52.5 \%$ & $56.4 \%$ & NA \\
\hline \multirow[t]{3}{*}{ study (\% of patients) $)^{57}$} & $20 \mathrm{mg} 37.9 \%$ & $15.9 \%$ & $33.0 \%$ & $45.5 \%$ & $40.0 \%$ & \\
\hline & $40 \mathrm{mg} 38.9 \%$ & $5.6 \%$ & $34.3 \%$ & $29.9 \%$ & $27.2 \%$ & \\
\hline & $80 \mathrm{mg}$ NA & NA & $28.6 \%$ & $11.4 \%$ & $6.7 \%$ & \\
\hline
\end{tabular}

*Statistically significant compared to the rosuvastatin $40 \mathrm{mg}$ PPO daily; $\mathrm{P}<0.002$ is statistically significant. ${ }^{8}$ 
( $115 \mathrm{mg} / \mathrm{dL}$ ) was achieved by $79 \%$ to $92 \%$ in rosuvastatin groups compared with $52 \%$ to $81 \%$ in atorvastatin groups (Table 1).

A possible explanation for better LDL cholesterol lowering efficacy of rosuvastatin and atorvastatin may lie in their pharmacodynamic properties. Their half-life is much longer than that of the other statins (19 and 14 hours respectively vs $1.5-3$ hours for the rest). ${ }^{13}$

The efficacy of $2 \mathrm{mg}$ daily of pitavastatin has been compared to $20 \mathrm{mg}$ of simvastatin daily in a prospective, randomized, open-label phase III trial. ${ }^{16}$ The percent LDL cholesterol reduction achieved was comparable in both groups (mean [SD], 38.2\% [11.6\%] for the pitavastatin group vs $39.4 \%$ [12.9\%] for the simvastatin group $[\mathrm{p}=0.648]) .{ }^{16}$ In another study, ${ }^{17}$ the efficacy of $2 \mathrm{mg}$ of pitavastatin $(\mathrm{n}=88)$ was evaluated in a 52-week, randomized, open-label, parallel-group study in comparison with $10 \mathrm{mg}$ daily of atorvastatin $(\mathrm{n}=85)$. Atorvastatin $10 \mathrm{mg} /$ day lowered LDL cholesterol more significantly than pitavastatin $(-40.1$ vs -33.0 , respectively; $p=0.002)$, but effects on HDL were more pronounced in the pitavastatin group $(8.2 \%$ vs $2.9 \%$ increase, respectively; $\mathrm{p}=0.031){ }^{17}$

\section{CVD risk reduction}

Multiple, well-designed, double-blind, placebo-controlled studies have documented significant cardiovascular risk reduction in patients in primary and secondary prevention groups by lowering of LDL cholesterol by statins. ${ }^{4-6,18-25}$ Meta-analysis of 19 studies (10 of them statin trials) ${ }^{26}$ in 81,859 participants with stable CHD showed that each $1 \%$ reduction in serum cholesterol level has been associated with about $1 \%$ reduction in risk of $\mathrm{CHD}$. The findings were consistent in statin and non-statin trials, suggesting that there was no additional pleiotropic effect from statin therapy beyond LDL cholesterol reduction. The findings did not differ for primary or secondary prevention. ${ }^{26,27}$ More recent meta-analysis of 14 statin $(n=100,827), 7$ fibrates $(n=21,647)$, and 6 niacin $(n=4445)$ trials, and 1 trial each of a bile acid sequestrant $(\mathrm{n}=3806)$, diet $(\mathrm{n}=458)$, and ileal bypass surgery $(\mathrm{n}=838)$ detected the same relationship. ${ }^{28}$

There is a wealth of evidence that statins have not only cholesterol lowering properties, but anti-inflammatory action and direct effects on endothelial function. One study evaluated the effect of statins on global inflammatory gene expression in vivo and found that some, but not most, were moderately downregulated by rosuvastatin and simvastatin. This result suggested that most anti-inflammatory effects of statins are exerted at the post-transcriptional level. ${ }^{29}$ The study by Shioto ${ }^{30}$ suggests that many statin pleiotropic effects are through the activation of AKT-mediated pathways. This includes an increase of eNOS activity via heat-shock protein 90 (HSP 90), which increases nitric oxide production, protein synthesis and cell proliferation via mammalian target of rapamycin (mTOR) pathway and activation of S6K. Statins affect the cytoskeletal proteins that play an important role in cell migration. ${ }^{30}$ The role of statins is expanding due to their multiple pleiotropic effects. Some reports suggest the effectiveness of statins in improving bone mineral density and healing after osteoporotic fractures, ${ }^{31}$ and use for systemic sclerosis and Raynaud's phenomenon, ${ }^{32}$ rheumatoid arthritis, and other conditions including Alzheimer's disease and even cancers. $^{33}$

With sustained reductions of total and LDL cholesterol levels over time, the risk of CVD mortality and CVD events declines. Meta-analysis of 58 trials (76,359 subjects on different types of therapy and 71,962 controls) showed that for each LDL cholesterol reduction of $1.0 \mathrm{mmol} / \mathrm{L}$, the risk of CVD events was reduced by $11 \%$ in the first year of treatment, $24 \%$ in the second year, $33 \%$ in years 3 to 5 , and by $36 \%$ thereafter ( $\mathrm{p}<0.001$ for trend). There was again no difference in the mode of cholesterol reduction. Half the patients had prior CVD and there was no difference in reported improvement between the two groups. ${ }^{15}$

A meta-analysis has also been used to assess effects of statin therapy (alone) in primary prevention (cardiovascular mortality and morbidity), and included 20 studies with more than 65,000 subjects. ${ }^{34}$ The relative risk (RR) of all cause mortality was 0.93 (95\% CI 0.87-0.99, p = 0.03); of CVD mortality 0.89 (95\% CI 0.81-0.98, $\mathrm{p}=0.01)$; of myocardial infarction (MI)-attributed mortality 0.46 (95\% CA 0.26-0.79, $\mathrm{p}=0.005)$ and acute MI $0.77(95 \%$ CI $0.63-0.95, \mathrm{p}=0.01) .{ }^{24}$ However, this meta-analysis did not included studies with simvastatin, pitavastatin or rosuvastatin, since at the time of publication no trials had met the inclusion criteria.

Recently the results of Justification for the Use of Statins in Prevention: an Intervention Trial Evaluating Rosuvastatin (JUPITER) became available. ${ }^{35}$ This study evaluated the effect of $20 \mathrm{mg}$ of rosuvastatin daily in healthy men and women (8901 on active medication and 8901 in placebo group) with entry median LDL cholesterol of $108 \mathrm{mg} / \mathrm{dL}$ (untreated), but with elevated high specificity C-reactive protein (HSCRP) (median $4.2 \mathrm{mg} / \mathrm{L}$ ). Primary outcomes included non-fatal MI, non-fatal stroke, hospitalization for angina, arterial revascularization procedures, or confirmed death from CVD causes. After median follow-up of 1.9 years, the Steering Committee decided to stop the trial 
on the recommendation of the Safety and Data Monitoring Board because of a significant cardiovascular benefit in the treated patients. Patients in the rosuvastatin group had a $44 \%$ reduction in primary end points (hazard ratio [HR] 0.56 , 95\% CI 0.46-0.69, p < 0.00001). ${ }^{35}$ Unlike the meta-analysis results, ${ }^{15,36}$ JUPITER showed more a pronounced reduction of cardiovascular hazard. For $1 \mathrm{mmol} / \mathrm{L}(38.7 \mathrm{mg} / \mathrm{dL})$ of LDL cholesterol decrease there was almost twice as previously reported $(\sim 20 \%)$ decline of vascular risk. In the Jupiter study, there was no difference in subgroup analysis in reduction of risk for CVD events, including subgroups evaluated by traditional risk factors and Framingham risk score. ${ }^{35}$ The results of the Jupiter study raise several important questions:

1. Are currently recommended LDL cholesterol goals appropriate, particularly in primary prevention, or should they be substantially lowered?

2. Do we need to set the lower standards for even healthy people with elevated HSCRP to achieve reduction of CVD events in primary prevention settings?

3. Does HSCRP have any direct effect on the cardiovascular system, or is it just a marker of an inflammatory state?

The Air Force/Texas Coronary Atherosclerosis Prevention Study (AFCAPS/TexCAPS) ${ }^{24,37}$ revealed that otherwise healthy patients with baseline LDL cholesterol less than $3.89 \mathrm{mmol} / \mathrm{L}(150 \mathrm{mg} / \mathrm{dL})$ and low HSCRP (less than $1.6 \mathrm{mg} / \mathrm{L}$ ) had no significant CVD event reduction after a year of $20 \mathrm{mg} /$ day lovastatin therapy. Overall, the effect of lovastatin therapy on HSCRP was about $15 \%$ reduction by the end of the 1-year treatment period; however, there was no correlation between LDL cholesterol and CRP reduction. ${ }^{37}$ Other statins as well are associated with significant reduction of HSCRP levels. ${ }^{38}$ In the meta-analysis ${ }^{39}$ of 23 studies with 57 treatment groups (58\% statin-only group and $23 \%$ ezetimide in combination with statin) the reduction of HSCRP depended on magnitude of LDL cholesterol reduction, rather than mode of reduction. According to Kinlay et $\mathrm{al}^{39}$ the relationship can be detected more easily in meta-analysis, since in smaller studies it can be diluted. The high correlation between changes in LDL cholesterol and CRP $(r=0.80, p<0.001)$ strongly support a causal link between changes in LDL cholesterol and arterial inflammation in atherosclerosis. ${ }^{39}$ A recent longitudinal study reported that incorporation of HSCRP into the risk stratification algorithm modestly improves detection of patients at higher risk, who otherwise would have been missed compared to the traditional risk assessment. ${ }^{40}$ An algorithm incorporating HSCRP and parental history improved risk prediction $5.3 \%$ overall and $14.2 \%$ for patients at intermediate risk by traditional risk scores (both $\mathrm{p}<0.001){ }^{40}$

There is a direct effect of statins (rosuvastatin, atorvastatin, simvastatin and pravastatin) on CRP production by human hepatocytes. ${ }^{41-43}$

Statins not only lower LDL cholesterol, but have effects on the size and concentration of LDL particles. The study by $\mathrm{Ai}$ et $\mathrm{al}^{44}$ in 271 hyperlipidemic men and women showed significant alteration of LDL cholesterol composition by maximal doses of rosuvastatin (40 mg/day) and atorvastatin $(80 \mathrm{mg} / \mathrm{dL})$. Rosuvastatin was more effective in reducing small dense LDL cholesterol over the course of 6 weeks $(53 \%$ vs $46 \%, \mathrm{p}<0.01) .{ }^{44}$ Both statins favorably affected the subpopulation of HDL particles. ${ }^{44}$

The recent Consensus Statement from the American Diabetes Association and the American College of Cardiology ${ }^{46,47}$ foundation examined several questions:

1. To what extent do lipoproteins contribute to CVD?

2. What are the clinically important lipoprotein parameters?

3. What are the principles and objectives of treatment of lipoprotein abnormalities?

The statement addressed the issue of global cardiometabolic risk (GCMR). Factors contributing to the GCMR include genetics, age, lifestyle as well as the presence of insulin resistance syndrome, hypertension, abnormal lipids, pro-inflammatory, and hypercoagulable states. The recommendations included an assessment of GCMR followed by a multifactorial risk reduction strategy. In terms of dyslipoproteinemia, statin therapy was recommended for the majority of patients with GCMR. In patients with dyslipidemia, the evaluation of not only total and LDL cholesterol concentrations but non-HDL cholesterol, apoB concentration by means of direct measurement, or evaluation of LDL particle number by nuclear magnetic resonance assay was suggested. Previously, several studies found that LDL particle numbers may be a better predictor of CVD events than LDL cholesterol or non-HDL cholesterol concentration. ${ }^{45}$ The ADA Consensus statement also suggested conducting "clinical trials to determine if pharmacological therapy required to achieve very low levels of atherogenic lipoproteins is safe and cost-effective." 46,47

\section{Slowing of the progression of atherosclerosis}

The Reversal of Atherosclerosis with Aggressive Lipid Lowering (REVERSAL) study ${ }^{6}$ was the first to indicate that statins may not only reduce the cholesterol level, but as well slow the progression of atheroma volume as 
assessed by intravascular ultrasound (IVUS) examinations at baseline and after 18 months of treatment. IVUS provides a precise and reproducible method for determining the change in atheroma burden during treatment. Six hundred fifty-seven patients (502 completed the study) with mean LDL cholesterol of $3.89 \mathrm{mmol} / \mathrm{L}(150.2 \mathrm{mg} / \mathrm{dL})$ were randomized to $40 \mathrm{mg}$ of pravastatin or $80 \mathrm{mg}$ of atorvastatin per day. The pravastatin group $(\mathrm{n}=549)$ achieved LDL cholesterol reduction down to $2.85 \mathrm{mmol} / \mathrm{L}$ $(110 \mathrm{mg} / \mathrm{dL})$ and the atorvastatin group $(\mathrm{n}=253)$ down to $2.05 \mathrm{mmol} / \mathrm{L}(79 \mathrm{mg} / \mathrm{dL})(\mathrm{p}<0.001)$. The percentage change in atheroma volume showed a progression of coronary atherosclerosis in the pravastatin group $(2.7 \%$; $95 \%$ confidence interval $[\mathrm{CI}], 0.2 \%-4.7 \% ; \mathrm{p}=0.001)$ compared with baseline and absence of progression in the atorvastatin group $(-0.4 \% ; \mathrm{CI}-2.4 \%$ to $1.5 \% ; \mathrm{p}=0.98)$ compared with baseline. ${ }^{6}$

The Study to Evaluate the Effect of Rosuvastatin on Intravascular Ultrasound-Derived Coronary Atheroma Burden (ASTEROID trial) ${ }^{48}$ included 349 patients with at least one vessel with $20 \%-50 \%$ luminal narrowing in any coronary artery. Participants were treated with a $40-\mathrm{mg}$ dose of rosuvastatin for 2 years. The initial median LDL cholesterol was $3.28 \mathrm{mmol} / \mathrm{L}(127 \mathrm{mg} / \mathrm{dL})$ and during treatment $1.5 \mathrm{mmol} / \mathrm{L}(58 \mathrm{mg} / \mathrm{dL})$, representing a $53.2 \%$ reduction from baseline $(\mathrm{p}<0.001)$. The ASTEROID trial reported regression of percent atheroma volume and total atheroma volume compared with the baseline $(\mathrm{p}<0.001$ for both); $63.6 \%$ of participants showed reduction of the percent atheroma volume. The ASTEROID authors also examined correlations between mean LDL cholesterol levels and median change in percent atheroma volume in several IVUS trials. A close correlation was observed $\left(r^{2}=0.97\right)$. The level at which percent atheroma volume was 0 corresponded to the LDL cholesterol level about $2.02 \mathrm{mmol} / \mathrm{L}$ (78 $\mathrm{mg} / \mathrm{dL}$ ). This suggests that to achieve clinically significant reduction in cholesterol burden, a LDL cholesterol level of less than $2.02 \mathrm{mmol} / \mathrm{L}(78 \mathrm{mg} / \mathrm{dL})$ would need to be attained and sustained over time. ${ }^{48}$

IVUS is an expensive and invasive procedure associated with certain complications (such as bleeding, reaction to IV contrast) and therefore, currently, not a practical modality to use clinically for follow up on atheroma burden. Other modalities have been studied in order to evaluate the effect of statins on atherosclerosis progression. Measurement of carotid intima media thickness (cIMT) has proven to be a safe, but controversial method as a surrogate for coronary artery disease. The clinical trials ARBITER, ${ }^{49}$ METEOR, ${ }^{50,51}$
$\mathrm{ACADIM}^{52}$ and $\mathrm{SANDS}^{53}$ have demonstrated the reduction of cIMT in both, high risk and low risk patients. ${ }^{54}$

\section{Real life goal attainment}

As reviewed above, cholesterol lowering with 3-hydroxy3-methylglutaryl-coenzyme A (HMG-CoA) reductase inhibitors reduces vascular events significantly in primary and secondary prevention of CHD. But how does it translate into a real life practice? Several studies have addressed this question. A European survey was conducted under the auspices of the European Society of Cardiology (ESC) to describe the treatment of hyperlipidemia among CHD patients in Europe. ${ }^{55}$ The first EUROASPIRE survey took place in 1995 to 1996 and the second survey was carried out in 1999 to 2000 in 15 European countries and enrolled 8181 patients with known CHD. Medical records were assessed at least 6 months (median time 1.4 years) after the CVD event and clinical examinations of risk factors including serum lipids were performed. While $89.2 \%$ of the whole cohort needed cholesterol-lowering medication, 68.3\% received it, and of these only 50.6\% achieved lipid-lowering goals. Of patients on lipid-lowering medications, statins were preferred and were used alone or in combination in $91.7 \%$ of patients. The results varied considerably between countries. The most frequently used doses of lipid-lowering agents were much lower than the doses of proven effective doses used in clinical trials. ${ }^{55,56}$ The 9 countries that participated in both EUROASPIRE I and II surveys showed that there had been a significant increase in the proportion of patients reaching the total cholesterol goal $<5.0 \mathrm{mmol} / \mathrm{L}$. The number of subjects treated and at the total cholesterol goal increased from $21 \%$ to $49 \% .{ }^{56}$ This is a great improvement, but leaves half the patients short of optimal cholesterol levels. A larger European observational trial, Return on Expenditure Achieved for Lipid Therapy (REALITY) included about 58,000 patients, mostly from general practice offices, from 10 different countries. ${ }^{57}$ They were followed for an average of 15.3 months between 1998 and 2001 . About $89 \%$ of patients were started on statins, mostly at low doses and only $40.5 \%$ achieved the goal of total cholesterol $<5.0 \mathrm{mmol} / \mathrm{L}$. The important finding of this study was the poor goal achievement in high-risk patients with known CHD (less than 30\%), which may indicate the presence of an intrinsically more complex lipid disorder, under-treatment, or a combination of both. Less than $20 \%$ patients had their doses titrated up even when they were not at the target, and even less were on combinational therapy. Interestingly, the goal attainment did not increase with statin potency. Atorvastatin was effective in 
$56.4 \%$ of subjects at its lowest dose of $10 \mathrm{mg}$ daily and only $6.7 \%$ in patients on $80 \mathrm{mg}$ a day (Table 1). This was most likely due to more severe hypercholesterolemia in patients on a higher statin dose. ${ }^{57}$

As in clinical trial settings, in real life settings patients who achieved better cholesterol control had reduction of risk of hospitalization for CVD ( $p=0.05)$. Among French patients, the incidence of CVD events was much less in patients who achieved the LDL cholesterol goal $(5.5 \%$ vs $12.9 \%$ of patients not at treatment goal during any of 3 years of observation, $\mathrm{p}=0.01$ ). In Sweden the risk of major CVD events was significantly lower $(24 \%)$ in patients who met the therapeutic target than in those who did not. Cardiovascular hospitalization cost was significantly lower at 2 to 3 years for achievers vs non-achievers. ${ }^{57}$

More recent findings from Italy indicate an increased use of statins when compared to all the prescriptions written in 1994 to $2003 .{ }^{58}$ The prevalence of statin use increased from $1.1 \%$ in 1994 to $4.35 \%$ in 2003 . Importantly, only half the patients who started on statins continued on the medication after 1 year. The cohort of 10,890 Italian patients was evaluated for adherence to statin therapy. Among the subjects in the primary prevention group $(n=8681), 56 \%$ were taking statins less than half the time, and only $19 \%$ of patients were adherent to the regimen. In the secondary prevention group $(\mathrm{n}=3209), 41 \%$ of patients took the medication more than $80 \%$ of time ( $p<0.001)$. Younger people (less than 54 years) had worse compliance than patients older than 64 years (53\% vs $46 \%$ respectively, $\mathrm{p}<0.001) .{ }^{58}$ However, this study did not address the causes of poor compliance or drug cessation. A Canadian study tried to evaluate different causes of discontinuation of statin therapy. ${ }^{59}$ Patients in primary prevention rather than secondary prevention groups (HR 1.18; 1.11-1.25) and older patients were more likely to continue the therapy than a younger cohort (HR 0.99; 0.98-0.99). Subjects with diabetes, hypertension, respiratory disease and on antidepressants and overall having a greater number of different classes of drugs ( $\geq 3$ ) taken were less likely to stop the cholesterol lowering medications. The total number of daily drug doses (HR 1.18; 1.15-1.20) significantly increases the rate of cessation. ${ }^{59}$

Female sex was associated with lower adherence than male sex. However, statins are class $\mathrm{C}$ during pregnancy and a feasible explanation is that younger women have less adherence to the medication while they are in child-bearing age. The concurrent use of birth control pill and HRT indeed increased the compliance to suggested statin doses according to this study's results.
Subjects living in a rural environment (HR 0.89; $0.85-0.94)$ were also less likely to cease their statin agents. Subjects receiving social assistance (HR 1.01; 0.96-1.07) were not associated with a better or lower cessation rate.

The factors that increase the chances of therapy cessation included use of multiple pharmacies or multiple prescribing physicians (HR 1.76; 1.65-1.89 and HR 1.77; 1.66-1.89 respectively. ${ }^{59}$ However, this study did not address the issue of drug discontinuation due to adverse effects or ineffectiveness. In clinical trials of statins, the drop out rate is generally around $3 \%$ to $9 \%$, but clinical trial populations are usually much more closely selected and homogeneous than conventional clinical practice cohorts. ${ }^{12,35,51}$

Pedan et al studied statin adherence in a US cohort, and detected that a higher co-pay and lower number of prescribed refills were likely to be associated with non-adherence. ${ }^{60}$ Surprisingly, patients, who were given a 90-day supply (and therefore, most likely a 1-year refill) were excluded from this study. Physicians who prescribed less statins had higher patient adherence rates and pharmacies that dispensed more statins had better patient adherence. The authors speculated that physicians who wrote the most statin prescriptions were more likely to work in the primary care settings and therefore had less time to spend with patients, rather than specialists. ${ }^{60}$ Unfortunately, this study did not have data on specialty of physicians included in the study.

Riesen et al tried to assess whether use of a compliance tool would improve the adherence to the rosuvastatin. ${ }^{51}$ Compliance tools included: a) a starter pack for subjects containing a videotape, an educational leaflet, a passport/goal diary and details of the help-line and/or website; b) regular personalized letters to provide message reinforcement; c) a toll-free help-line and a website. The adherence in both interventional and control groups was very high (around 97\%-100\%) and, therefore, intervention with compliance tools did not improve the clinical outcomes of LDL cholesterol goal reduction. ${ }^{51}$ However, this was a clinical trial and not a real life situation and it would be interesting to have studies done including similar compliance kits to evaluate if this translates into improvement of statin adherence in real life settings.

\section{Conclusion}

Statins are safe and effective therapy for reduction of myocardial infarction, ischemic stroke, and peripheral vascular events in primary and secondary settings. The effect is more pronounced after sustained lipid lowering for 1.5 to 2 years. Rosuvastatin appears to be the most effective 
statin currently available on the market for lowering LDL cholesterol, and at higher doses, increases HDL cholesterol rather than decreases it, as is often the case for atorvastatin or simvastatin at the $80 \mathrm{mg}$ level. Rosuvastatin was effective in reducing CVD events in healthy patients with currently "normal" levels of LDL cholesterol but high HSCRP.

Having safe and effective statins for LDL cholesterol lowering has the potential to substantially reduce cardiac and ischemic stroke event rates, but, in the clinical setting, the rate of statin discontinuation is very high and overall adherence to the medical regimen is low. To reduce discontinuation and improve adherence we would recommend the education of pharmacists, physicians and patients concerning persistence with treatment. At least 2 to 3 years of consistent LDL cholesterol lowering are needed to see significant reduction in CVD events and atheroma burden.

\section{Practical pearls}

Provide more refills at the original prescription. Try to use a once-daily formulation.

Cheapest co-pay will be more likely associated with better adherence.

Work more closely with women and younger population in primary prevention settings for adherence.

\section{Disclosures}

The authors disclose no conflicts of interest.

\section{References}

1. Ohsfeldt RL, Gandhi SK, Fox KM, Stacy TA, McKenney JM. Effectiveness and cost-effectiveness of rosuvastatin, atorvastatin, and simvastatin among high-risk patients in usual clinical practice. Am J Manag Care. 2006;12:S412-S423.

2. Ward S, Lloyd Jones M, Pandor A, et al. A systematic review and economic evaluation of statins for the prevention of coronary events. Health Technol Assess. 2007;11:1-160, iii-iv.

3. Lewington S, Whitlock G, Clarke R, et al. Blood cholesterol and vascular mortality by age, sex, and blood pressure: a meta-analysis of individual data from 61 prospective studies with 55,000 vascular deaths. Lancet. 2007;370:1829-1839.

4. Cannon $\mathrm{CP}$, Braunwald $\mathrm{E}, \mathrm{McCabe} \mathrm{CH}$, et al. Intensive versus moderate lipid lowering with statins after acute coronary syndromes. $N$ Engl $J$ Med. 2004;350:1495-1504.

5. LaRosa JC, Grundy SM, Waters DD, et al. Intensive lipid lowering with atorvastatin in patients with stable coronary disease. $N$ Engl $J$ Med. 2005;352:1425-1435.

6. Nissen SE, Tuzcu EM, Schoenhagen P, et al. Effect of intensive compared with moderate lipid-lowering therapy on progression of coronary atherosclerosis: a randomized controlled trial. JAMA. 2004;291:1071-1080.

7. Grundy SM, Cleeman JI, Merz CN, et al. Implications of recent clinical trials for the National Cholesterol Education Program Adult Treatment Panel III Guidelines. J Am Coll Cardiol. 2004;44:720-732.

8. Jones PH, Davidson MH, Stein EA, et al. Comparison of the efficacy and safety of rosuvastatin versus atorvastatin, simvastatin, and pravastatin across doses (STELLAR* Trial). Am J Cardiol. 2003;92:152-160.
9. Graham I, Atar D, Borch-Johnsen K, et al. European guidelines on cardiovascular disease prevention in clinical practice: executive summary. Atherosclerosis. 2007;194:1-45.

10. Tobert JA. Lovastatin and beyond: the history of the HMG-CoA reductase inhibitors. Nat Rev Drug Discov. 2003;2:517-526.

11. Press Release. Recordati S.p.A: Obtains European Licence for Pitavastatin. 2008. Accessed 02/21/2009;Available from http://biz.yahoo. com/iw/081024/0446144.html.

12. Jacobson TA. Statin safety: lessons from new drug applications for marketed statins. Am J Cardiol. 2006;97:44C-51C.

13. Clinical implications of drug interactions with statin therapy-a guide to optimizing care and decreasing risk for adverse events. National Lipid Association, 2008. Accessed 01/05/2009;Available from http://www. lipid.org/clinical/insights/1000013.php.

14. Shitara Y, Sugiyama Y. Pharmacokinetic and pharmacodynamic alterations of 3-hydroxy-3-methylglutaryl coenzyme A (HMG-CoA) reductase inhibitors: drug-drug interactions and interindividual differences in transporter and metabolic enzyme functions. Pharmacol Ther. 2006;112:71-105.

15. Law MR, Wald NJ, Rudnicka AR. Quantifying effect of statins on low density lipoprotein cholesterol, ischaemic heart disease, and stroke: systematic review and meta-analysis. BMJ. 2003;326:1423.

16. Park S, Kang HJ, Rim SJ, et al. A randomized, open-label study to evaluate the efficacy and safety of pitavastatin compared with simvastatin in Korean patients with hypercholesterolemia. Clin Ther. 2005;27:1074-1082.

17. Sasaki J, Ikeda Y, Kuribayashi T, et al. A 52-week, randomized, open-label, parallel-group comparison of the tolerability and effects of pitavastatin and atorvastatin on high-density lipoprotein cholesterol levels and glucose metabolism in Japanese patients with elevated levels of low-density lipoprotein cholesterol and glucose intolerance. Clin Ther. 2008;30:1089-1101

18. Influence of pravastatin and plasma lipids on clinical events in the West of Scotland Coronary Prevention Study (WOSCOPS). Circulation. 1998;97:1440-1445.

19. MRC/BHF Heart Protection Study of cholesterol lowering with simvastatin in 20,536 high-risk individuals: a randomised placebo-controlled trial. Lancet. 2002;360:7-22.

20. Colhoun HM, Betteridge DJ, Durrington PN, et al. Primary prevention of cardiovascular disease with atorvastatin in type 2 diabetes in the Collaborative Atorvastatin Diabetes Study (CARDS): multicentre randomised placebo-controlled trial. Lancet. 2004;364:685-696.

21. Randomised trial of cholesterol lowering in 4444 patients with coronary heart disease: the Scandinavian Simvastatin Survival Study (4S). Lancet. 1994;344:1383-1389.

22. Sacks FM, Pfeffer MA, Moye LA, et al. The effect of pravastatin on coronary events after myocardial infarction in patients with average cholesterol levels. Cholesterol and Recurrent Events Trial investigators. N Engl J Med. 1996;335:1001-1009.

23. Prevention of cardiovascular events and death with pravastatin in patients with coronary heart disease and a broad range of initial cholesterol levels. The Long-Term Intervention with Pravastatin in Ischaemic Disease (LIPID) Study Group. N Engl J Med. 1998;339:1349-1357.

24. Downs JR, Clearfield M, Weis S, et al. Primary prevention of acute coronary events with lovastatin in men and women with average cholesterol levels: results of AFCAPS/TexCAPS. Air Force/Texas Coronary Atherosclerosis Prevention Study. JAMA. 1998;279:1615-1622.

25. Sever PS, Dahlof B, Poulter NR, et al. Prevention of coronary and stroke events with atorvastatin in hypertensive patients who have average or lower-than-average cholesterol concentrations, in the Anglo-Scandinavian Cardiac Outcomes Trial - Lipid Lowering Arm (ASCOT-LLA): a multicentre randomised controlled trial. Lancet. 2003;361:1149-1158.

26. Robinson JG, Smith B, Maheshwari N, Schrott H. Pleiotropic effects of statins: benefit beyond cholesterol reduction? A meta-regression analysis. J Am Coll Cardiol. 2005;46:1855-1862.

27. LaRosa JC. Low-density lipoprotein cholesterol reduction: the end is more important than the means. Am J Cardiol. 2007;100:240-242. 
28. Robinson JG, Wang S, Smith BJ, Jacobson TA. Meta-analysis of the relationship between non-high-density lipoprotein cholesterol reduction and coronary heart disease risk. J Am Coll Cardiol. 2009;53:316-322.

29. Schmidt WM, Spiel AO, Jilma B, Wolzt M, Muller M. In-vivo effects of simvastatin and rosuvastatin on global gene expression in peripheral blood leucocytes in a human inflammation model. Pharmacogenet Genomics. 2008;18:109-120.

30. Shiota M, Kusakabe H, Hikita Y, Nakao T, Izumi Y, Iwao H. Pharmacogenomics of cardiovascular pharmacology: molecular network analysis in pleiotropic effects of statin - an experimental elucidation of the pharmacologic action from protein-protein interaction analysis. J Pharmacol Sci. 2008;107:15-19.

31. Tang QO, Tran GT, Gamie Z, et al. Statins: under investigation for increasing bone mineral density and augmenting fracture healing. Expert Opin Investig Drugs. 2008;17:1435-1463.

32. Abou-Raya A, Abou-Raya S, Helmii M. Statins: potentially useful in therapy of systemic sclerosis-related Raynaud's phenomenon and digital ulcers. J Rheumatol. 2008;35:1801-1808.

33. Paraskevas KI, Tzovaras AA, Briana DD, Mikhailidis DP. Emerging indications for statins: a pluripotent family of agents with several potential applications. Curr Pharm Des. 2007;13:3622-3636.

34. Mills EJ, Rachlis B, Wu P, Devereaux PJ, Arora P, Perri D. Primary prevention of cardiovascular mortality and events with statin treatments: a network meta-analysis involving more than 65,000 patients. $J \mathrm{Am}$ Coll Cardiol. 2008;52:1769-1781.

35. Ridker PM, Danielson E, Fonseca FA, et al. Rosuvastatin to prevent vascular events in men and women with elevated C-reactive protein. N Engl J Med. 2008;359:2195-2207.

36. Baigent C, Keech A, Kearney PM, et al. Efficacy and safety of cholesterol-lowering treatment: prospective meta-analysis of data from 90,056 participants in 14 randomised trials of statins. Lancet. 2005;366:1267-1278

37. Ridker PM, Rifai N, Clearfield M, et al. Measurement of C-reactive protein for the targeting of statin therapy in the primary prevention of acute coronary events. N Engl J Med. 2001;344:1959-1965.

38. Koshiyama H, Taniguchi A, Tanaka K, et al. Effects of pitavastatin on lipid profiles and high-sensitivity CRP in Japanese subjects with hypercholesterolemia: Kansai Investigation of Statin for Hyperlipidemic Intervention in Metabolism and Endocrinology (KISHIMEN) investigatars. J Atheroscler Thromb. 2008;15:345-350.

39. Kinlay S. Low-density lipoprotein-dependent and -independent effects of cholesterol-lowering therapies on C-reactive protein: a meta-analysis. J Am Coll Cardiol. 2007;49:2003-2009.

40. Ridker PM, Paynter NP, Rifai N, Gaziano JM, Cook NR. C-reactive protein and parental history improve global cardiovascular risk prediction: the Reynolds Risk Score for men. Circulation. 2008;118:2243-2251, $4 \mathrm{p}$ following 51 .

41. Mayer C, Gruber HJ, Landl EM, et al. Rosuvastatin reduces interleukin-6-induced expression of C-reactive protein in human hepatocytes in a STAT3- and C/EBP-dependent fashion. Int J Clin Pharmacol Ther. 2007;45:319-27.

42. Voleti B, Agrawal A. Statins and nitric oxide reduce C-reactive protein production while inflammatory conditions persist. Mol Immunol. 2006;43:891-896.

43. Arnaud C, Burger F, Steffens S, et al. Statins reduce interleukin6-induced C-reactive protein in human hepatocytes: new evidence for direct antiinflammatory effects of statins. Arterioscler Thromb Vasc Biol. 2005;25:1231-1236.

44. Ai M, Otokozawa S, Asztalos BF, et al. Effects of maximal doses of atorvastatin versus rosuvastatin on small dense low-density lipoprotein cholesterol levels. Am J Cardiol. 2008;101:315-318.
45. Superko HR, Gadesam RR. Is it LDL particle size or number that correlates with risk for cardiovascular disease? Curr Atheroscler Rep. 2008;10(5):377-385.

46. Brunzell JD, Davidson M, Furberg CD, et al. Lipoprotein management in patients with cardiometabolic risk: consensus conference report from the American Diabetes Association and the American College of Cardiology Foundation. J Am Coll Cardiol. 2008;51:1512-1524.

47. Brunzell JD, Davidson M, Furberg CD, et al. Lipoprotein management in patients with cardiometabolic risk: consensus statement from the American Diabetes Association and the American College of Cardiology Foundation. Diabetes Care. 2008;31:811-822.

48. Nissen SE, Nicholls SJ, Sipahi I, et al. Effect of very high-intensity statin therapy on regression of coronary atherosclerosis: the ASTEROID trial. JAMA. 2006;295:1556-1565.

49. Taylor AJ, Kent SM, Flaherty PJ, Coyle LC, Markwood TT, Vernalis MN. ARBITER: Arterial Biology for the Investigation of the Treatment Effects of Reducing Cholesterol: a randomized trial comparing the effects of atorvastatin and pravastatin on carotid intima medial thickness. Circulation. 2002;106:2055-2060.

50. Crouse JR, 3rd, Raichlen JS, Riley WA, et al. Effect of rosuvastatin on progression of carotid intima-media thickness in low-risk individuals with subclinical atherosclerosis: the METEOR Trial. JAMA. 2007;297: 1344-1353.

51. Riesen WF, Noll G, Dariolo R. Impact of enhanced compliance initiatives on the efficacy of rosuvastatin in reducing low density lipoprotein cholesterol levels in patients with primary hypercholesterolaemia. Swiss Med Wkly. 2008;138:420-426.

52. Riccioni G, Bazzano LA, Bucciarelli T, Mancini B, di Ilio E, D’Orazio N. Rosuvastatin reduces intima-media thickness in hypercholesterolemic subjects with asymptomatic carotid artery disease: the Asymptomatic Carotid Atherosclerotic Disease in Manfredonia (ACADIM) Study. Expert Opin Pharmacother. 2008;9:2403-2408.

53. Fleg JL, Mete M, Howard BV, et al. Effect of statins alone versus statins plus ezetimibe on carotid atherosclerosis in type 2 diabetes: the SANDS (Stop Atherosclerosis in Native Diabetics Study) trial. J Am Coll Cardiol. 2008;52:2198-2205.

54. Kastelein JJ, de Groot E, Sankatsing R. Atherosclerosis measured by B-mode ultrasonography: effect of statin therapy on disease progression. Am J Med. 2004;116 Suppl 6A:31S-36S.

55. Kotseva K, Stagmo M, De Bacquer D, De Backer G, Wood D. Treatment potential for cholesterol management in patients with coronary heart disease in 15 European countries: findings from the EUROASPIRE II survey. Atherosclerosis. 2008;197:710-717.

56. Clinical reality of coronary prevention guidelines: a comparison of EUROASPIRE I and II in nine countries. EUROASPIRE I and II Group. European Action on Secondary Prevention by Intervention to Reduce Events. Lancet. 2001;357:995-1001.

57. Van Ganse E, Laforest L, Alemao E, Davies G, Gutkin S, Yin D. Lipid-modifying therapy and attainment of cholesterol goals in Europe: the Return on Expenditure Achieved for Lipid Therapy (REALITY) study. Curr Med Res Opin. 2005;21:1389-1399.

58. Deambrosis P, Saramin C, Terrazzani G, et al. Evaluation of the prescription and utilization patterns of statins in an Italian local health unit during the period 1994-2003. Eur J Clin Pharmacol. 2007;63: 197-203.

59. Perreault S, Blais L, Lamarre D, et al. Persistence and determinants of statin therapy among middle-aged patients for primary and secondary prevention. Br J Clin Pharmacol. 2005;59:564-573.

60. Pedan A, Varasteh L, Schneeweiss S. Analysis of factors associated with statin adherence in a hierarchical model considering physician, pharmacy, patient, and prescription characteristics. J Manag Care Pharm. 2007;13:487-496. 